\title{
Cystic fibrohistiocytic tumour of the lung presenting with recurrent pneumothorax: a case report
}

\author{
Christos Kakos $^{1}$, Savvas Lampridis ${ }^{2}$, Georgios Geropoulos ${ }^{2}$, Reena Khiroya ${ }^{3}$, Achilleas Antonopoulos ${ }^{2}$, \\ Sofoklis Mitsos ${ }^{2}$, Nikolaos Panagiotopoulos ${ }^{2}$
}

${ }^{1}$ Department of Cardiothoracic Surgery, Royal Victoria Hospital, Belfast; ${ }^{2}$ Department of Thoracic Surgery, University College London Hospitals NHS Foundation Trust, London; ${ }^{3}$ Department of Histopathology, University College London Hospitals NHS Foundation Trust, London, UK

\begin{abstract}
Cystic fibrohistiocytic tumour of the lung is a very rare pathological entity that occurs either as a primary pulmonary neoplasm or as a metastasis from skin lesions called cellular fibrous histiocytomas. Herein, we present the case of a 19-year old man with a history of recurrent pneumothoraces who was managed surgically
\end{abstract}

Correspondence: Christos Kakos, Ulster Hospital, Dundonald, Belfast, BT16 1RH, UK

Tel.+44.7397314648. E-mail: kakoschristos91@gmail.com

Keywords: cystic fibrohistiocytic tumour; lung; pneumothorax; cutaneous fibrohistiocytic tumour; case report.

Contributions: CK, conception and design, collection and assembly of data; GG, CK, administrative support; RK, CK, provision of study materials or patients; SL, CK, data analysis and interpretation. All authors, manuscript drafting and reviewing. All the authors have read and approved the final version of the manuscript and agreed to be accountable for all aspects of the work.

Conflict of interest: the authors declare no conflict of interest.

Funding: This research did not receive any specific grant from funding agencies in the public, commercial, or not-for-profit sectors.

Patient consent for publication: Written informed consent was obtained from the patient for publication of this Case Report and accompanying images. A copy of the written consent is available for review by the Editor-in Chief of this journal on request.

Conference presentation: This case report was presented as an e-poster at the $11^{\text {th }}$ Congress of the Hellenic Society of Thoracic \&

Cardiovascular Surgeons on 24-26 November 2016.

Received for publication: 21 May 2020.

Accepted for publication: 1 July 2020.

${ }^{\circ}$ Copyright: the Author(s), 2020

Licensee PAGEPress, Italy

Monaldi Archives for Chest Disease 2020; 90:1398

doi: 10.4081/monaldi.2020.1398

This article is distributed under the terms of the Creative Commons Attribution Noncommercial License (by-nc 4.0) which permits any noncommercial use, distribution, and reproduction in any medium, provided the original author(s) and source are credited. and was eventually diagnosed with cystic fibrohistiocytic tumour of the lung. Clinicians should include this disease in the differential diagnosis of pulmonary cystic lesions and be aware of its association with cellular fibrous histiocytoma. Reporting of more cases is warranted to further elucidate the natural course of the disease and optimise its management.

\section{Introduction}

Cystic fibrohistiocytic tumour of the lung is an extremely rare neoplasm. It commonly represents metastatic disease from cellular fibrous histiocytomas, which are benign cutaneous lesions with low-grade malignant potential [1]. Occasionally, it develops as a primary lung tumour. Herein, we present the case of a young man with pulmonary cystic fibrohistiocytic tumour who presented with recurrent pneumothoraces and received surgical treatment. We subsequently review the pertinent literature to elucidate the epidemiology and establish the management of this rare disease.

\section{Case Report}

A 19-year-old man, who had undergone video-assisted thoracoscopic pleurectomy for previous episodes of right-sided pneumothorax, presented to the Emergency Department with a new episode of ipsilateral pneumothorax. His relevant past medical history included asthma. The patient reported removal of a skin lesion from the left shoulder a few years ago. It was benign and cystic in nature, as reported by the patient, but no official histopathology report was found. A chest radiograph demonstrated a large right-sided pneumothorax, which was initially managed with insertion of an intercostal chest drain. A computed tomography (CT) scan of the chest revealed multiple cystic foci within both lungs, the largest of which was associated with the left oblique fissure and measured approximately $16 \mathrm{~mm}$ (Figure 1). The cysts were thin-walled and were distributed bilaterally, mainly in the upper and middle zones. Some of these cysts had an irregular outline. No other focal or diffuse pulmonary abnormality or thoracic lymphadenopathy were detected.

The patient underwent repeat video-assisted thoracoscopic excision of the remaining pleura and talc pleurodesis. An immediate postoperative chest radiograph demonstrated a large left-sided pneumothorax, which resolved with insertion of an intercostal chest drain. The patient was discharged on the second postopera- 
tive day. A week later, he underwent the same surgical procedure on the left side and was discharged after 48 hours.

The histopathological analysis of the specimens obtained from both lungs revealed multiple, peripherally located, enlarged cystic air spaces. The walls of the cysts were lined by cuboidal epithelial cells, with evidence of squamous metaplasia in some areas. Beneath the surface of the cysts, there was characteristic fibrohistiocytic spindle cell proliferation, which was cytologically bland with no mitotic activity (Figure 2A). Within these areas, there was a rich vascular network. The spindle cells had high nuclear-cytoplasmic ratio, inconspicuous nucleoli and minimal amount of cytoplasm. The spindle cell proliferation was also outspread to the visceral pleura. Immunohistochemical studies showed that these cells were focally positive for CD68 (Figure 2B) and negative for cytokeratins, desmin, smooth muscle actin, CD34, S100 and CD1a.

The patient underwent genetic testing to assist in the final diagnosis of his pathology. Testing for tuberous sclerosis complex $1 \&$ 2 genes (TSC1 \& TSC2) to rule out pulmonary lymphangioleiomyomatosis was negative. Similarly, testing for folliculin gene
(FLCN), which is responsible for Birt-Hogg-Dubé syndrome, was also negative.

The patient suffered a further episode of right-sided pneumothorax which was managed with repeat video-assisted thoracoscopic talc pleurodesis. The patient is alive after 4 years, remains on regular follow up and has not received any further treatment to date. Serial dermatologic examinations did not reveal further cutaneous lesions. The multiple pulmonary cystic lesions, which were detected on his initial admission, remained stable in subsequent CT imaging.

\section{Discussion}

Cystic fibrohistiocytic tumour of the lung is a very rare neoplasm. Morphological and immunohistochemical evidence suggest that this tumour usually derives from cutaneous cellular fibrous histiocytomas (dermatofibromas) [2-6]. However, there is a small number of cases of cystic fibrohistiocytic tumour of the lung where

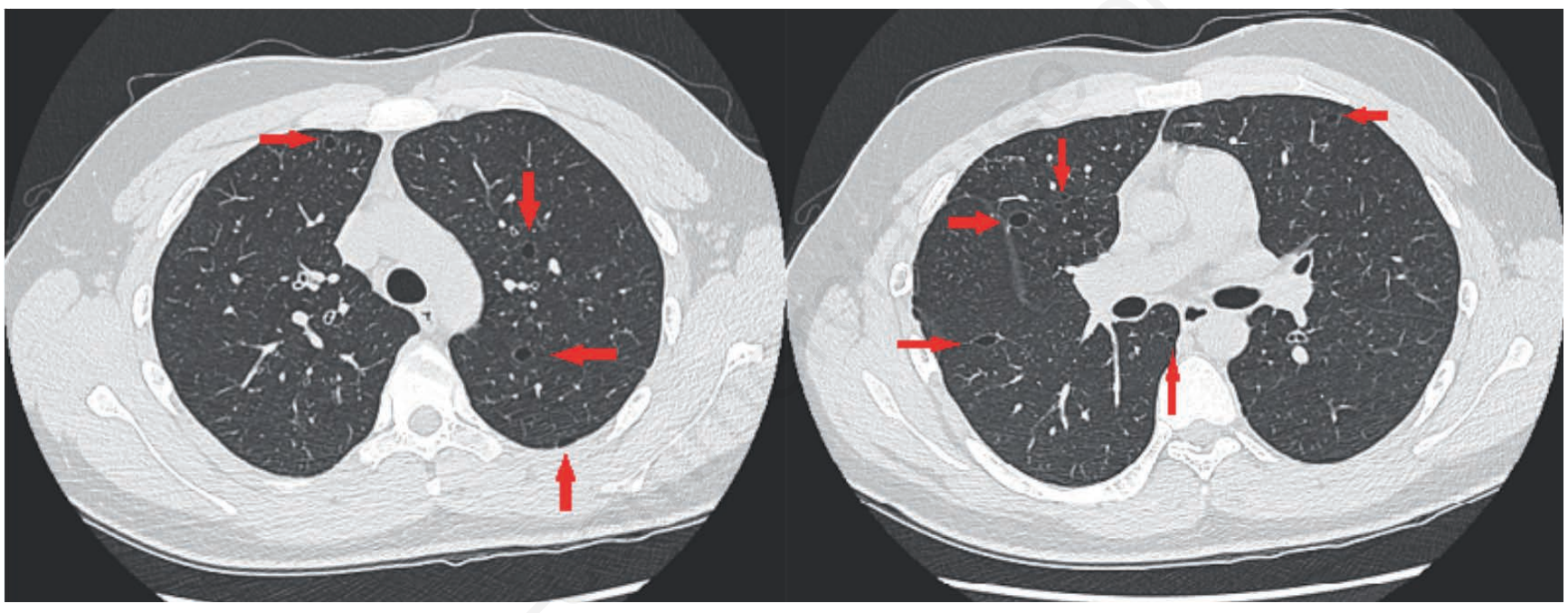

Figure 1. Axial computed tomographic images of the chest demonstrating multiple parenchymal cysts in both lungs (red arrows).
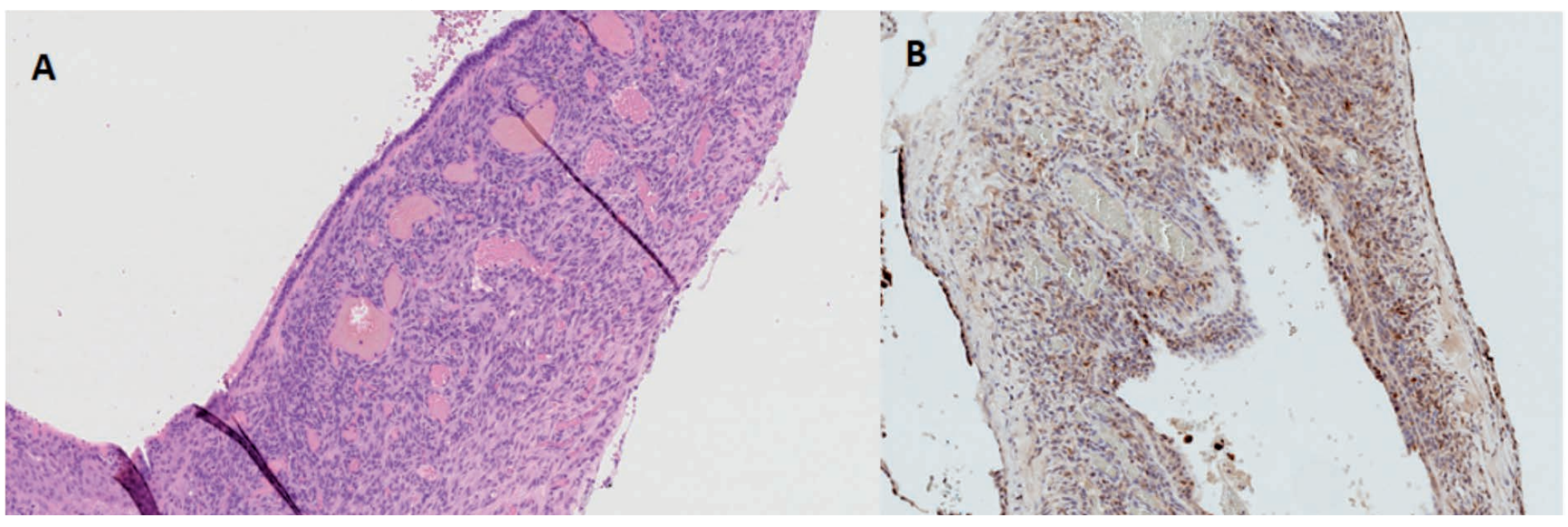

Figure 2. A) H\&E staining (1000x magnification): Cystic space surrounded by bland spindle cell proliferation. B) Immunohistochemical stain for CD68 (1100x magnification): CD68 shows focal positive staining within the spindle cell areas. 
no skin lesion was identified [1,2,7-9]. These cases can be interpreted as primary pulmonary neoplasms or as cases where the primary skin lesion is occult [1].

Cystic fibrohistiocytic tumour of the lung was first by Holden et al. in 1982 [8]. Since then, 15 more cases, including ours, have been published (Table 1). Only lesions that were cystic in histology have been included in the table. The mean age of presentation was 33 years (range, 16-65 years), with a male predominance (3:1). The main clinical manifestations included pneumothorax $(40 \%)$ and haemoptysis (20\%), symptoms identified in other cystic lung diseases. The remaining $40 \%$ of the patients had no symptoms from the respiratory system, and the tumour was diagnosed incidentally or in the context of surveillance following resection of cutaneous fibrous histiocytoma. On CT scan of the chest, cystic fibrohistiocytic tumours usually appeared as bilateral multiple cystic foci or nodular opacities. In one case, however, the tumour presented as a solitary pulmonary nodule [7]. The overall prognosis was excellent; of 13 patients, all were alive at a median follow-up of 2 years (interquartile range, 1-4.5 years).

The diagnosis of cystic fibrohistiocytic tumour of the lung is confirmed with histopathological and immunohistochemical studies. Macroscopically, this neoplasm usually presents as multiple enlarged cystic nodules in the pulmonary parenchyma. Microscopically, these lesions are lined by cuboidal and squamous epithelial cells, while the intervening stroma shows characteristic proliferation of cytologically bland spindle cells mixed with histocytes, lymphocytes and plasma cells. The lesions are characterized by rich vasculature without evidence of necrosis or lymphovascular invasion. The immunohistochemical labelling is also typical, as the epithelial cells are TTF1+, which suggests origin from the alveolar parenchyma. Moreover, the spindle cells are usually CD68+, while the cystic lesions are not stained for CD34, S100, desmin, smooth muscle actin, cytokeratins, EMA, factor VIII or CD1a $[1,5,7]$.

The differential diagnosis includes Langerhans cell granulomatosis, lymphangioleiomyomatosis, pleuropulmonary blastoma, metastatic low-grade sarcoma, mesenchymal cystic amartoma, benign uterine leiomyoma and uterine sarcoma [6,9]. Radiologically, the differential diagnosis could also include cystic amyloidosis and gastrointestinal malignancies. Clinical features, morphological characteristics and immunohistochemical analysis can help differentiate between these entities.

Cellular fibrous histiocytomas belong to a greater family of neoplasms called cutaneous fibrohistiocytic tumours, which share

Table 1. Demographic and clinical characteristics of published cases of cystic fibrohistiocytic tumour of the lung presenting as cystic pulmonary lesions.

\begin{tabular}{|c|c|c|c|c|c|c|c|c|}
\hline First author & Year & Age & Sex & $\begin{array}{l}\text { Radiological/histopathological } \\
\text { findings }\end{array}$ & $\begin{array}{l}\text { Primary } \\
\text { tumour }\end{array}$ & $\begin{array}{l}\text { Cutaneous } \\
\text { lesions }\end{array}$ & $\begin{array}{l}\text { Respiratory } \\
\text { symptoms }\end{array}$ & Follow-up \\
\hline Holden [8] & 1982 & 25 & M & Bilateral diffuse thin-walled cavities & Yes & No & Haemoptysis & Alive at 5 years \\
\hline \multirow[t]{2}{*}{ Joseph [2] } & 1990 & 65 & M & $\begin{array}{l}\text { Bilateral multiple nodular lesions, } \\
\text { cystic on microscopy }\end{array}$ & Yes & No & $\begin{array}{l}\text { None (incidental } \\
\text { finding on } \\
\text { routine CXR) }\end{array}$ & Alive at 2 years \\
\hline & & 30 & M & Bilateral multiple cystic lesions & No & $\begin{array}{l}\text { Recurrent } \\
\text { dermatofibromas }\end{array}$ & Pneumothorax & Alive at 20 years \\
\hline \multirow[t]{2}{*}{ Colome-Grimmer [3] } & 1996 & 18 & M & Bilateral lung lesions, cystic on microscopy & No & CFH 1.5 years ago & $\begin{array}{l}\text { None } \\
\text { (FU post removal } \\
\text { of CFH) }\end{array}$ & Alive at 4 years \\
\hline & & 33 & M & Bilateral lung lesions, cystic on microscopy & No & CFH 1 year ago & $\begin{array}{l}\text { None (FU post } \\
\text { removal of CFH) }\end{array}$ & Alive at 8 years \\
\hline Colby [4] & 1997 & 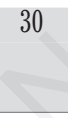 & $\mathrm{F}$ & Bilateral multiple cystic lesions & No & $\begin{array}{l}\text { Dermatofibro- } \\
\text { sarcoma protuberans } \\
17 \text { years ago }\end{array}$ & $\begin{array}{l}\text { Pneumothorax } \\
\text { s }\end{array}$ & NK \\
\hline \multirow[t]{4}{*}{ Osborn [1] } & 2003 & 38 & M & Bilateral nodular and cavitating opacities & Yes & No & Haemoptysis & Alive at 2 years \\
\hline & & 54 & M & Bilateral nodular and cavitating opacities & No & $\begin{array}{l}\text { CFH removed } 2,9 \\
\text { and } 23 \text { years ago }\end{array}$ & Haemoptysis & Alive at 4 years \\
\hline & & 35 & M & Bilateral multiple cystic lesions & Yes & No & NK & Alive at 1 year \\
\hline & & 29 & M & Bilateral multiple cavitary lesions & No & $\begin{array}{l}\text { CFH removed } \\
10 \text { years ago }\end{array}$ & $\begin{array}{l}\text { Pneumothorax } \\
\text { pneumonia, }\end{array}$ & NK \\
\hline DiGiovine [9] & 2004 & 35 & $\mathrm{~F}$ & Unilateral multiple cystic lesions & Yes & No & $\begin{array}{l}\text { Chest pain, } \\
\text { dyspnoea, } \\
\text { pneumothorax }\end{array}$ & Alive at 1 year \\
\hline $\mathrm{Gu}[5]$ & 2007 & 36 & $\mathrm{~F}$ & Bilateral multiple cystic lesions & No & CFH 7 years ago & $\begin{array}{l}\text { None (incidental } \\
\text { finding) }\end{array}$ & Alive at 1 year \\
\hline Casero [6] & 2009 & 37 & $\mathrm{~F}$ & Bilateral multiple cystic lesions & No & $\begin{array}{l}\text { CFH } 6 \text { years ago, } \\
\text { recurrence on } \\
\text { diagnosis }\end{array}$ & $\begin{array}{l}\text { None (FU post } \\
\text { removal of CFH) }\end{array}$ & Alive at 9 months \\
\hline Paci [7] & 2010 & 16 & M & Single cystic lesion & Yes & No & Pneumothorax & Alive at 2 years \\
\hline Present study & 2020 & 19 & M & Bilateral multiple cystic lesions & No & $\begin{array}{l}\text { Yes, unknown } \\
\text { histology }\end{array}$ & Pneumothorax & Alive at 4 years \\
\hline
\end{tabular}

CFH, cellular fibrous histiocytoma; CXR, chest radiograph; FU, follow-up; NR, not reported; NK, not known. 
similar clinical, morphological and molecular characteristics [10]. The literature suggests that these tumours tend to metastasise either locally or systemically and usually have an indolent course $[1-3,5,6,11]$. However, a more aggressive clinical behaviour cannot be ruled out by the histopathological characteristics of these neoplasms. All of the above render their diagnosis challenging leading to potential underreporting of this entity. Therefore, it is deemed necessary to establish frequent and close follow-up of patients with cutaneous fibrohistiocytic tumours who underwent surgical resection even with negative margins [11]. Adjuvant chemotherapy has been associated with poor results; however, little evidence exists regarding its use [6,12].

\section{Conclusions}

Cystic fibrohistiocytic tumour of the lung is a rare proliferative disease and represents an infrequent cause of spontaneous pneumothorax. When treating patients with pulmonary cystic lesions, clinicians must include this disease in the differential diagnosis. Moreover, they should be knowledgeable of its association with cutaneous cellular fibrous histiocytoma. The rarity of pulmonary cystic fibrohistiocytic tumours in combination with the lack of well-defined diagnostic criteria have probably led to underreporting of this neoplasm. Reporting of more cases along with longer patient follow-up are needed to further understand the natural course of the disease and optimise its management.

\section{References}

1. Osborn M, Mandys V, Beddow E, et al. Cystic fibrohistiocytic tumours presenting in the lung: primary or metastatic disease? Histopathology 2003;43:556-62.

2. Joseph MG, Colby TV, Swensen SJ, et al. Multiple cystic fibrohistiocytic tumors of the lung: report of two cases. Mayo Clin Proc 1990;65:192-7.

3. Colome-Grimmer MI, Evans HL. Metastasizing cellular dermatofibroma: a report of two cases. Am J Surg Pathol 1996;20: 1361-7.

4. Colby TV. Metastasizing dermatofibroma. Am J Surg Pathol 1997;21:976.

5. Gu M, Sohn K, Kim D, Kim B. Metastasizing dermatofibroma in lung. Ann Diagn Pathol 2007;11:64-7.

6. Bermejo Casero E, Pérez Alonso D, Quevedo Losada S, López Rivero L. [Dermatofibroma metastasizing to the lung: current treatment].[Article in Spanish]. Arch Bronconeumol 2009;45: 521-3.

7. Paci M, Cavazza A, Annessi V, et al. Cystic fibrohistiocytic tumor of the lung presenting as a solitary lesion. Rare Tumors 2010;2:e14.

8. Holden WE, Mulkey DD, Kessler S. Multiple peripheral lung cysts and hemoptysis in an otherwise asymptomatic adult. Am Rev Respir Dis 1982;126:930-2.

9. Digiovine B, Stone C, Pai V. Primary cystic fibrohistiocystic tumor of the lung: An extremely rare cause of recurrent spontaneous pneumothorax. Chest 2004;126:990S.

10. Luzar B, Calonje E. Cutaneous fibrohistiocytic tumours - an update. Histopathology 2010;56:148-65.

11. De Hertogh G, Bergmans G, Molderez C, Sciot R. Cutaneous cellular fibrous histiocytoma metastasizing to the lungs. Histopathology 2002;41:85-6.

12. Dunkin C, MacGregor A, McLaren K. Metastasising dermatofibroma or dermatofibroma-like dermatofibrosarcoma protuberans? J R Coll Surg Edinb 2000;45:132-4. 